\title{
Preliminary report on climate risk in the \\ Cambridgeshire \& Peterborough region, 2020-2099
}

\author{
Dr Ethan D. Aines, ${ }^{\mathrm{a}}$, Dr Charles Simpson ${ }^{\mathrm{b}}$, \\ Dr Amy Munro-Faure ${ }^{a}$, \& Dr Emily Shuckburgh ${ }^{a}$
}

\section{Executive summary}

This report examines the interplay between two factors, future overheating and changes in seasonal rainfall patterns, and provides a preliminary overview of some of the major risks associated with these changes across the Cambridgeshire \& Peterborough region. Insight into the changing regional climate is provided through the UK Climate Projection 2018 (UKCP18) data and associated products and research.

- The region faces at least 42 local risks and opportunities of the 53 national risks referenced in the UK Climate Change Risk Assessment 2017.

- Of these, the most severe risks faced by the region before 2099 will relate to more extreme summer temperatures and changes in the character of seasonal and annual precipitation (rain, snow, hail, etc).

- By the end of the century, annual average rainfall may be greater than in the past between November and March, and may be greatly reduced from May to October.

- The region's extremely low-lying topography has led to well-documented severe flooding from both rivers and the sea, most notably in 1947, 1953, 1978, 1998, and 2001.

- Nearly 1 -in-10 homes and nearly 1 -in-4 agricultural and industrial production facilities may face flooding from rivers by 2099 due to changing precipitation patterns without further adaptation. Flooding from runoff in urban and paved areas may also impact a significantly higher proportion of the built environment.

- The region may also face tidal flooding from storm surges particularly at high tide if the Ouse and/or Nene rivers are already in flood. The risk of an increase in mean sea level by 2099 impacting future storm surges is currently imperfectly understood.

- Summers may face significantly higher extreme temperatures

- Due in part to greater future water needs, changes in the character of summer precipitation, and increased summer

${ }^{a}$ Cambridge Zero, University of Cambridge

${ }^{b}$ UKRI British Antarctic Survey temperatures, the region may seasonally experience lower river and aquifer levels than in years past. This, in turn, exposes the region to a number of risks across several crucial areas including people, businesses, industry, and biodiversity within the natural environment.

- Natural carbon storage areas-the remaining deep peat in the Fens-will continue to be depleted under most current management practices, and future climate in the region may lead to more rapid emissions of carbon from these areas. The Fens could be a net emitter of carbon in future, instead of a net absorber (or 'sinks'), if allowed to further dry. Further, without protection, the area of subsided land across the region could double, possibly before the end of the century.

\section{Future climate risk}

Climate in the UK, as globally, is incontrovertibly changing. The ten warmest years on record since 1884 have occurred since 2002 whereas none of the coldest years have occurred since 1963 (Kendon et al., 2019). Summers have been on average $11 \%$ wetter than 1981-2010 and 13\% wetter than 1961-1990 (ibid). A greater number of named storms have affected the UK in recent years than in the past (ibid). As the most recent UK Climate Change Risk Assessment from 2017 (CCRA17) makes clear, climate change is not only of future concern, but a present-day threat (UK Climate Change Risk Assessment 2017, 2017). The CCRA17 outlines 53 risks to the natural environment, to infrastructure, to people and the built environment, and to business and industry; at least 42 of these risks are locally important to the Cambridgeshire and Peterborough region (Table 1). Climate change may be global, but it will be experienced by people at a local level in rapidly approaching years.

This report provides a brief summary of some of the most severe risks facing the Cambridgeshire and Peterborough region. While it does not delve into the details of all 42 projected risks, it provides an outline of risks from both river ('fluvial') and run-off flooding, from tidal flooding, from overheating in the summer months, of low river and aquifer levels, and of damage to natural carbon storage areas in the 
Preliminary report on climate risk in the Cambridgeshire \& Peterborough region, 2020-2099

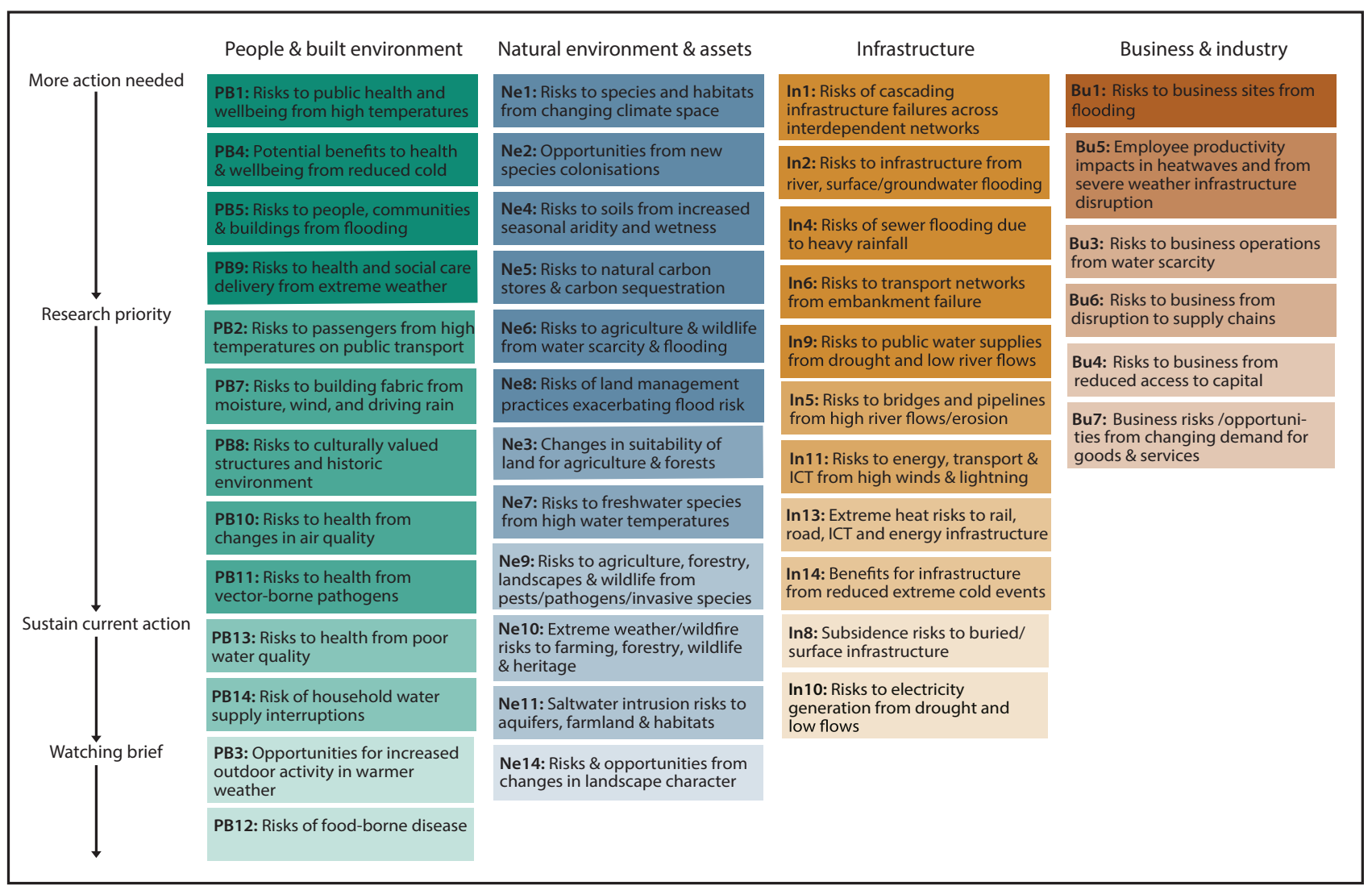

Table 1.42 climate risks and opportunities relevant to the Cambridgeshire \& Peterborough region, referenced from the 2017 UK Climate Change Risk Assessment. Risks related to international dimensions and costal erosion and flooding have been omitted as not specially relevant to the region. Color gradient (darkest to lightest) indicates level of national concern, from more action needed to watching brief. Reference numbers refer to national report. Source: Committee on Climate Change (2016) UK Climate Change Risk Assessment 2017 Synthesis Report.

deep peat of the Fens. Most of these risks may be represented by two figures that originate from the latest Met Office Hadley Centre UK Climate Projections from 2018 (UKCP18) regional models of the future climate: future extreme heating in summer (Fig. 1) and future rainfall anomaly (Fig. 2). As these downscaled, regional climate projections indicate, global warming will accelerate over the remainder of the century, and weather will depend strongly upon future atmospheric greenhouse-gas concentrations which are tied to emissions.

\section{A note on climate projections data and warming scenarios}

The desire to describe risks related to both a $2^{\circ}$ and $4^{\circ} \mathrm{C}$ warming scenario could not be met for this report because of data availability. UKCP18 data do not categorise their data products by warming scenarios, but instead by Representative Concentration Pathways (RCP). These are pathways adopted by the IPCC, which describe possible climate futures based on different future atmospheric greenhouse-gas concentrations.
Figures $1 \& 2$ are based on RCP 2.6, 4.5, 6.0, and 8.5. By the end of the century, these pathways will result in a global average temperature rise to a likely range of $0.3-1.7^{\circ} \mathrm{C}$ under the RCP 2.6 scenario to $2.6-4.8^{\circ} \mathrm{C}$ under RCP 8.5 (IPCC, 2013). It should be noted that the RCP 8.5 scenario has been critiqued as too extreme a scenario, and includes, for example, a highly unlikely future return to significant combustion of coal. Researchers have therefore emphasised that the RCP 8.5 scenario should not be included in policy studies (Ritchie \& Dowlatabadi, 2017). Nevertheless, certain regional UKCP18 data products include only RCP 2.6 \& RCP 8.5; therefore, it has been included here only as an upper benchmark that probably lies outside our true current trajectory.

\section{Future regional climate}

To briefly summarise future climate in the Cambridgeshire \& Peterborough region, summers may be hotter and drier than over the course of the last century (Lowe et al., 2018). Winters may also be milder and have the potential to be 


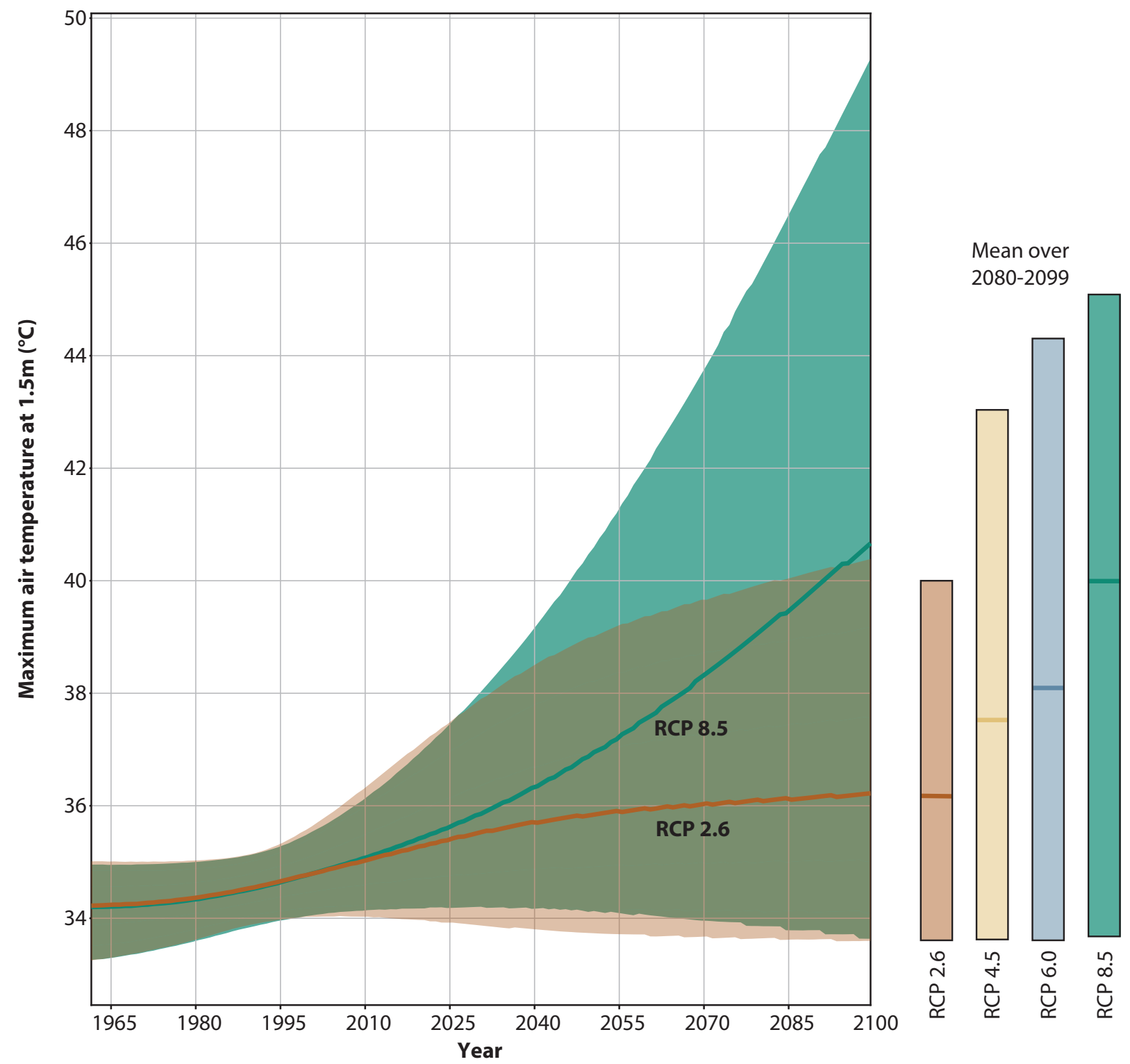

Figure 1. Projections of seasonal maximum air temperature at $1.5 \mathrm{~m}\left({ }^{\circ} \mathrm{C}\right)$ for June, July \& August across the Cambridgeshire \& Peterborough region from 1961 to 2099, for a return period of 20 years, relative to the 1981-2000 baseline, from the HadCM3 Model for RCP 2.6 \& 8.5. The range (5th-95th percentile) is shown as a shaded band. The ranges for the mean over the end-of-the-century period (2080-2099) for RCP scenarios 2.6, 4.5, 6.0, \& 8.5 are given as coloured vertical bars, with the corresponding median value given as a horizontal line. Note that temperatures in individual locations may be significantly hotter than the maximum air temperature averaged across the region. Contains Met Office data (UKCP18) licensed under the Open Government Licence v3.0.

much wetter (ibid). There will still be annual variations within these trends, as currently.

Future warming in the region and extreme summer temperatures will depend strongly upon emissions (Fig. 1). Under a stringent mitigation pathway (RCP 2.6), for the hotter climate of 2080-2099, the temperature in the hottest part of the day could be $36^{\circ} \mathrm{C}$ or higher for one in 20 years, and $40.5^{\circ} \mathrm{C}$ or higher for one in 20 years in RCP 8.5 , a pathway in which emissions continue to rise. However, as the shaded bands in Figure 1 indicate, there is a range of uncertainty and a chance of experiencing significantly hotter temperatures.

The current record summer air temperature in the region is $38.7^{\circ} \mathrm{C}$, set on July 25, 2019 in Cambridge. The future scenario will fall somewhere in the range between 

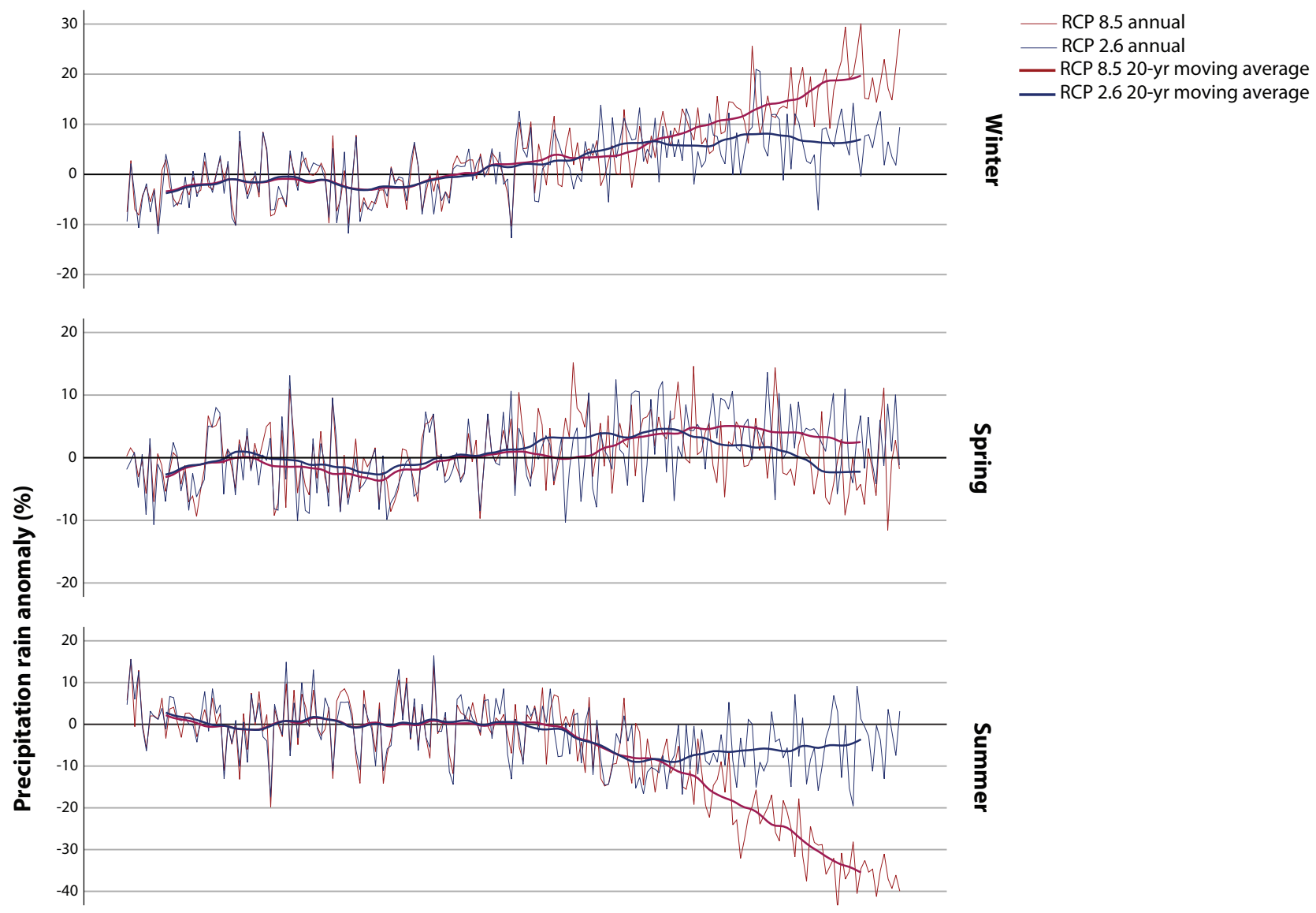

$\stackrel{n}{\frac{n}{3}}$
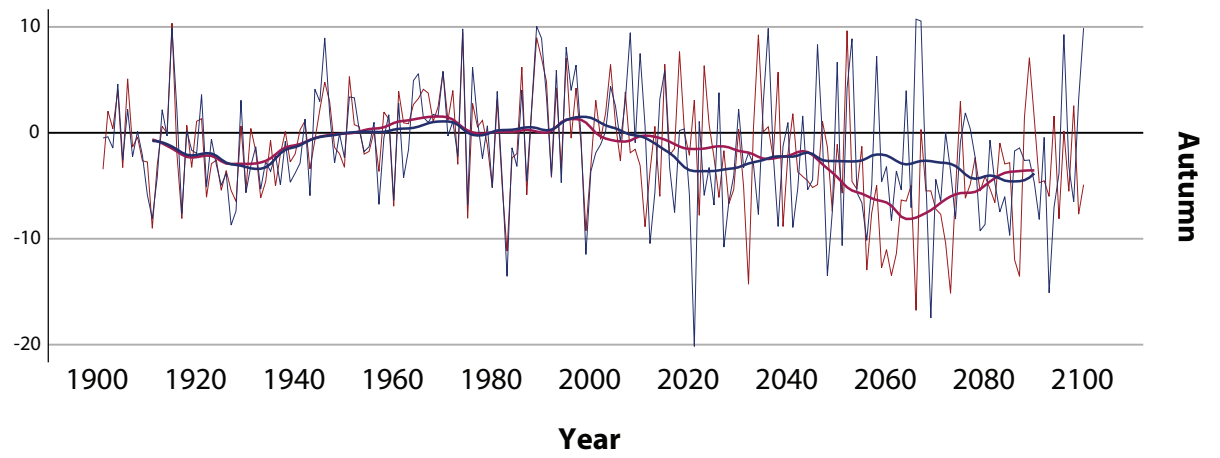

Figure 2. Multi-model mean of seasonal average precipitation rate anomaly, by season from 1900 to 2099, across the East of England river catchments including the Great Ouse \& Nene, using baseline 1981-2000, for scenarios RCP 2.6 \& 8.5. Contains Met Office data (UKCP18) licensed under the Open Government Licence v3.0, 2020.

RCP 2.6 and 8.5, with higher summer temperatures becoming more common. While the mid-century maximum air temperatures in Figure 1 may seem lower than the record regional high, it is important to note that temperatures in some locations will be well above the regional average. For example according to the ERA5 global reanalysis, on July 25, 2019, the maximum temperature averaged across the region was $34^{\circ} \mathrm{C} ; 4.7^{\circ} \mathrm{C}$ lower than the temperature at the Cambridge Botanical Garden weather station (Hersbach et al., 2020). This is because each station has some degree of microclimate. There may be a small urban heat island effect, and the weather station's position affects the amount of wind and sunlight it is exposed to. Therefore, summer highs at individual locations will be higher than the regional average high.

Additionally, as other research using the UKCP18 models makes clear, by the end of the century there may be between two to four times more summer days above $25^{\circ} \mathrm{C}$ in 
the region than there were in the past 30 years. Nearly a third of the UK, including the Cambridgeshire \& Peterborough region, would likely see average summer temperatures above $25^{\circ} \mathrm{C}$ in more severe scenarios by the end of the century (Dale \& Stylianou, 2020).

Changes in seasonal precipitation patterns could mean that winter floods and summer droughts will become more common in the Cambridgeshire \& Peterborough region (Fig. 2). In both the RCP 2.6 \& 8.5 scenarios, seasonal rainfall anomaly (the percentage above or below the regional historical baseline) will vary from historic levels in all seasons. In general, the months from November to March will see a greater amount of rainfall, while the months from May to September will see a decline in rainfall. Other research and reports have also emphasised that, while the winter rainfall anomaly may increase, rainfall could be less frequent and more intense during the winter months (Lowe et al., 2018; Adams 2020).

These two simple projections of changes in extreme summer temperatures and changes in annual precipitation patterns provide the basis for the following sections about risk to the region.

\section{Risk of fluvial flooding}

Both the Great Ouse and Nene catchments have a history of flooding. The most severe recent historic floods occurred in March 1947, Easter 1998, and October 2001 (River Nene Catchment Flood Management Plan: Managing Flood Risk, 2009; Great Ouse Catchment Flood Management Plan: Managing Flood Risk, 2011). Significant tidal flooding (see more below) has also occurred, most recently in 1953 and 1978 (ibid).

Using a basic method outlined in the University of Cambridge's Climate Change Risk and Resilience Scoping Study, completed by the consulting group Aecom, future flood risk from rivers (fluvial) may be represented through the proxy of the Environment Agency's (EA) flood maps for planning (Troshka et al., 2018). In this method, in lieu of a not-yet-implemented superior methodology, the EA's 1-in100 flood risk layer ( $1 \%$ annual risk) is used to represent a building's current exposure to flooding, and the 1-in-1000 flood risk layer ( $0.1 \%$ annual risk) is used to represent future exposure to flooding by 2099. In this methodology, the 1-in1000 risk ostensibly becomes the 1-in-100 risk by the end of the century, providing a very approximate overview of future flooding exposure. A Geographic Information Systems (GIS) database of all the current buildings in the Cambridgeshire \& Peterborough region, obtained from both the Ordnance Survey and Open Street Maps, was queried in order to quantify which buildings lie within the two flood risk layers. This preliminary method does not account for planned future development and it does not consider further adaptation. The results are presented in Tables $2 \& 3$ and in Figure 3 .

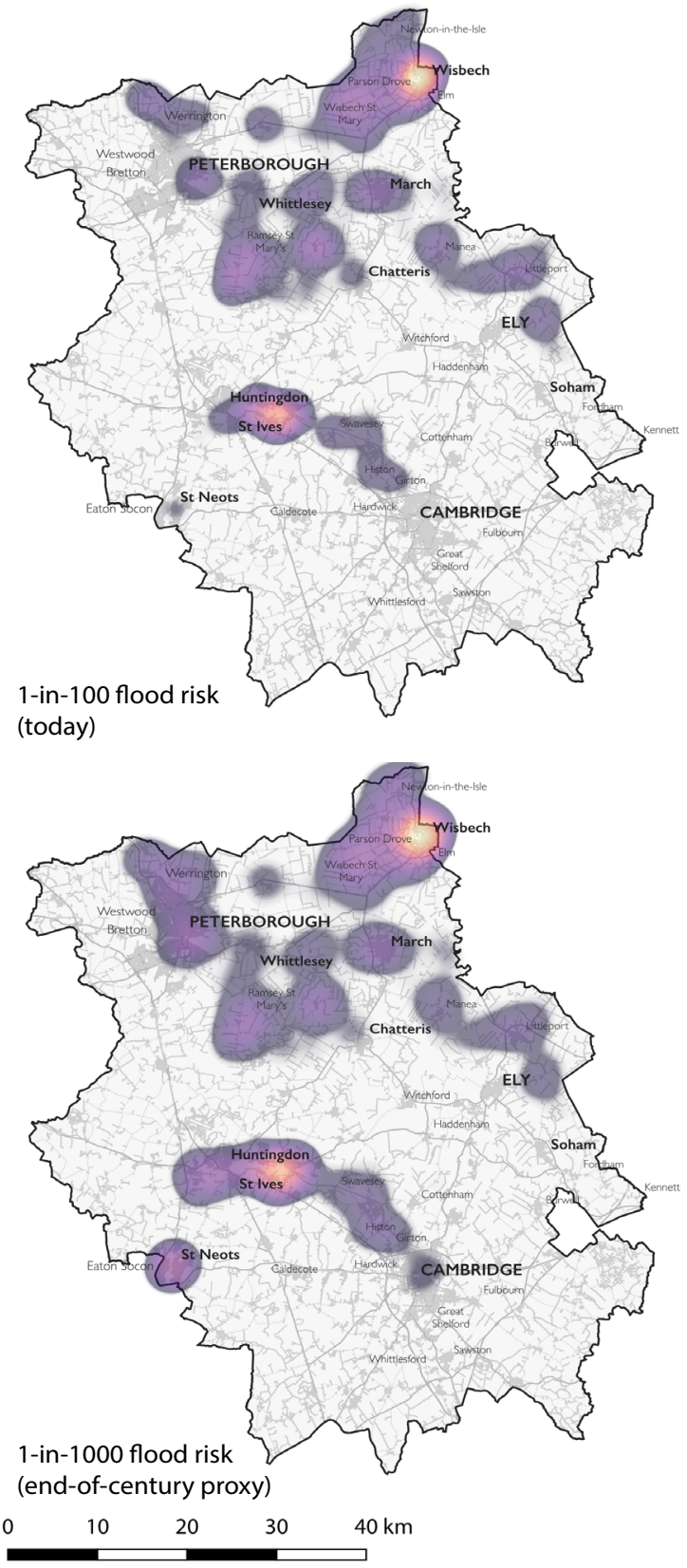

Figure 3. Heat-map detailing 1-in-100 (1\% annual chance) and 1-in-1000 (.1\% annual chance) risk of flooding for the Cambridgeshire \& Peterborough region. Warmer colours indicate greater density of buildings with exposure to flood risk. End of century flood risk has been represented assuming no further adaptation. Contains Ordnance Survey data (C) Crown copyright and database right 2020 (Digimap License). Contains public sector information licensed under the Open Government Licence v3.0 (Flood Map for Planning (Rivers and Sea) - Flood Zone 2 \& Flood Zone 3 Nov. 2020) () Environment Agency copyright and/or database right 2020. All rights reserved. 


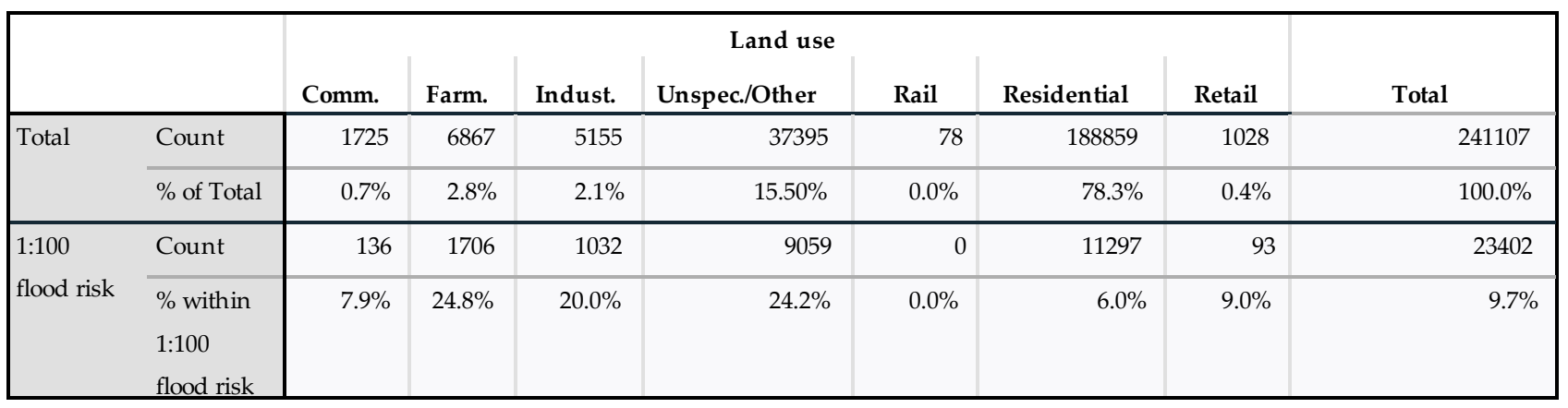

\begin{tabular}{|c|c|c|c|c|c|c|c|c|c|}
\hline & & \multicolumn{7}{|c|}{ Land use } & \multirow[b]{2}{*}{ Total } \\
\hline & & Comm. & Farm. & Indust. & Unspec./Other & Rail & Residential & Retail & \\
\hline \multirow[t]{2}{*}{ Total } & Count & 1725 & 6867 & 5155 & 37395 & 78 & 188859 & 1028 & 241107 \\
\hline & $\%$ of Total & $0.7 \%$ & $2.8 \%$ & $2.1 \%$ & $14.5 \%$ & $0.0 \%$ & $78.3 \%$ & $0.4 \%$ & $100.0 \%$ \\
\hline \multirow{2}{*}{$\begin{array}{l}\text { 1:1000 } \\
\text { flood risk }\end{array}$} & Count & 214 & 1974 & 1330 & 10507 & 3 & 17232 & 192 & 31452 \\
\hline & $\begin{array}{l}\text { \% within } \\
\text { 1:1000 } \\
\text { flood risk }\end{array}$ & $12.4 \%$ & $28.7 \%$ & $25.8 \%$ & $28.1 \%$ & $3.8 \%$ & $9.1 \%$ & $18.7 \%$ & $13.0 \%$ \\
\hline
\end{tabular}

Table 2 \& Table 3. A simple cross-tabulation of 1-in-100 (top) and 1-in-1000 (bottom) flood risk to structures categorised by land use type, across the Cambridgeshire and Peterborough region. Roads could not be included in this analysis because elevations of bridges and raised sections of highway are not known. Contains Ordnance Survey data (C Crown copyright and database right 2020 (Digimap License). Contains public sector information licensed under the Open Government Licence v3.0 (Flood Map for Planning (Rivers and Sea) - Flood Zone 2 \& Flood Zone 3 Nov.2020) (c) Environment Agency copyright and/or database right 2020. All rights reserved.

As Figure 3 details, the greatest number of properties with both current and future exposure to flood risk lie in the northern portion of the region. Throughout much of the region, the two flood risks virtually overlap because of the extremely low-lying topography. Approximately $10 \%$ of structures in the Cambridgeshire \& Peterborough region are currently at risk of flooding, and this number could be expected to expand to around 13\% (an increase of around 8,000 structures) by 2099: in other words a $30 \%$ increase in the number of structures at risk, again, in the absence of future development and adaptation. These numbers are sobering, indicating that by the end of the century, more than a quarter of the region's current industrial and farm buildings could be at risk of inundation, and nearly 1-in10 homes in the region could be threatened. Communities, farms, and industry in the areas of Wisbech, Whittlesey, Huntington, St. Ives, and the eastern edge of Peterborough face the highest risk.

A relatively small number (1\%) of buildings associated with functional sites-schools, universities, hospitals, police stations, etc-have exposure to flood risk at the 1-in-100 level, but without further adaptation measures this rises to $1.6 \%$ at the 1-in-1000 level: in other words there could be a $60 \%$ increase in the number of such buildings exposed to flood risk. Based on current locations at the 1-in-1000 level, this includes seven fire stations, four police stations, 48 buildings associated with higher education (primarily colleges at the University of Cambridge), four hospitals, including Addenbrookes and Royal Papworth, the St. Ives and Histon libraries, 11 post offices, 113 buildings associated with 41 primary \& secondary schools, and four sports \& leisure centres. Areas that are anticipated to be particularly hard-hit include Histon, Impington, Oakington, St. Ives, Wisbech, and Littleport.

Additionally, the risk of inundation of structures is only one of the risks associated with flooding. For example, the Great Ouse and Nene catchments comprise one of the most productive agricultural areas in the country, accounting for around half of the nation's highest quality land and producing more than one-third of England's vegetable crop (Great Ouse Catchment Flood Management Plan: Managing Flood Risk, 2011). Increased frequency of future flooding events may greatly impact both the region and nation's agricultural sector, in addition to populated areas and other industry. Furthermore, in the event of a flood warning, both industrial and farm production are impacted even if floodwaters do not rise, owing to the necessity of shutting down production and securing equipment. A future with 


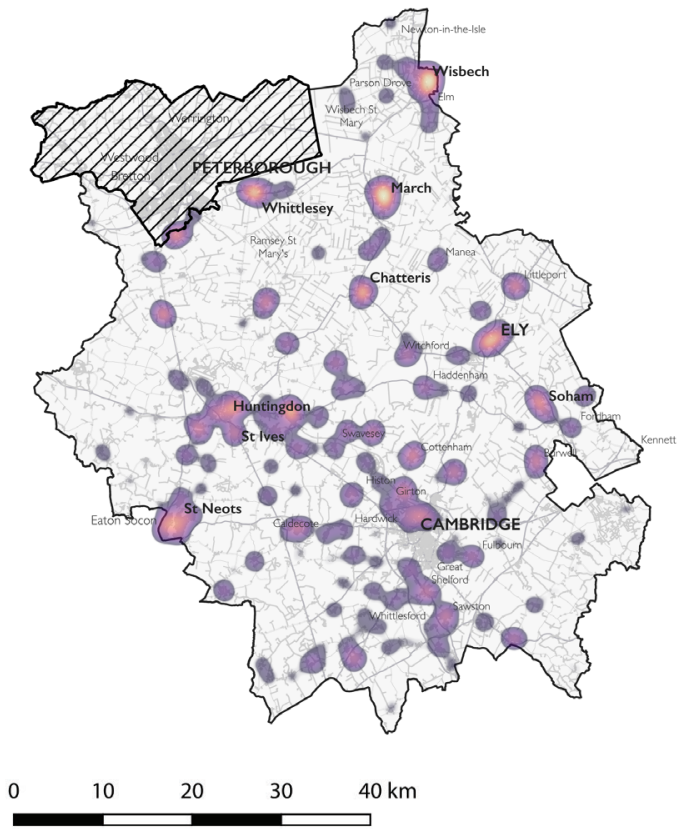

Figure 4. Heatmap detailing the current risk of flooding from surface water in Cambridgeshire (n.b. does not include Peterborough, which will be similarly at risk). Warmer colours indicate greater density of buildings with exposure to floodrisk. While this method does not consider future flood risk, these areas will be expected to flood more frequently in the future. Contains Ordnance Survey data (c) Crown copyright and database right 2020 (Digimap License). Contains Cambridgeshire County Council data, "Toal Countywide Wetspots" map layer, 2020. Contains public sector information licensed under the Open Government Licence v3.0.

a greater number of flood warnings would therefore also impact the region, particularly around Wisbech where a large number of industrial estates sit in the flood plain of the River Nene.

The risk discussed above only includes fluvial sources of flooding (ie river floods); there will also be greater future risk from surface water flooding. Although our preliminary report does not yet accurately quantify future risk from pluvial or runoff sources, (ie flash and surface water floods), Figure 4 presents a heatmap of the areas currently at risk from surface water flooding, using the Cambridgeshire County Council's "Countywide Wetspots Map" layer queried against the Ordnance Survey and Open Street Maps layers as for fluvial risk using GIS (n.b. Fig. 4 does not include Peterborough, though this will be amended in our wider report on risk; Peterborough, as an urban area, will face similar exposure to flooding from surface water as areas in Cambridgeshire).
To briefly summarise these results, $71 \%$ of all structures in Cambridgeshire lie in areas with the potential for surface water flooding. This crucially does not mean that $71 \%$ of buildings in Cambridgeshire will flood, as this very rudimentary metric cannot account for the specific situation of an individual property (eg whether it has a basement, at what height the building entrances sit above the street level, how deep water will be in these areas, etc). Using the EA's flood risk from surface water planning maps or machine learning to model flooding can help answer some of these questions; Cambridge Zero has not yet completed this work. A more refined answer to future fluvial (river) and pluvial (surface water) flood risk will be available in the mid-2021 report. Furthermore, the Cambridgeshire County Council surface water management plans which accompany the wetspots data provide much more detail on the range of functional sites at risk from surface flooding (Surface Water Management Plans, 2011).

Figure 4, although a rough method of estimation, highlights the extent to which pluvial flooding may be a greater future risk in most urban and suburban areas with poor drainage and impermeable paving than the risk from fluvial flooding, which is highly contextual.

Figure 2 provides a compelling projection of these future risks. Greater future rainfall anomaly in the winter and early spring may indicate a greater future risk of flooding; researchers have shown that even small increases in the intensity of rainfall can greatly impact flooding (ArnbjergNielsen et al., 2012). However, it should be noted that flooding is not always, or only, caused by higher rainfall anomaly: it is also connected with factors beyond precipitation variability, including snowmelt and groundwater abstraction (Smith \& Phillips, 2013). For example, the devastating March 1947 floods in East Anglia were caused primarily by snowmelt in early March and successive heavy rain later in the month (1947 UK River Floods: 60-Year Retrospective, 2007).

\section{Risk of tidal flooding}

Additionally, the risk of tidal flooding, as has occurred numerous times throughout the region's history-most recently in 1953, 1978, and 2013-must be considered. It should be noted that at its closest point to the Wash, Cambridgeshire is no more than $10 \mathrm{~km}$ from the coast at Foul Anchor in the Fenland District. Furthermore, the tidal stretch of the River Nene extends more than $30 \mathrm{~km}$ inland from Foul Anchor to the tidal defences outside Peterborough at Dog in a Doublet. The River Ouse begins its tidal extent near Earith, only $16 \mathrm{~km}$ from central Cambridge, despite the numerous controls on the Ouse Washes ( The Ouse Washes Flood Storage Reservoir, n.d.).

The 1953 storm and associated coastal flooding was the most severe flooding event of the 20th century in Britain (Baxter, 2005). It provides a template, along with the 1978 
flood, for understanding these events. Caused by extreme low-pressure, hurricane force winds, and a coincident high tide, water levels during the 1953 storm flooded land as high as $5.6 \mathrm{~m}$ above mean sea level at the coast. In Britain, 83,000 ha-or around 320 square miles-were flooded, and as many as 40,000 people were forced to evacuate, with thousands more made homeless (Steers, 1953). Approximately 1,600 km of coastline were damaged, and sea defences were breached in more than 1,200 locations along the North Sea coast of Britain (Prichard, 2013). All told, more than 2,000 people lost their lives to drowning and exposure around the North Sea Basin, and the event has been of central importance to flood risk management and mitigation in the intervening years (Wadey et al., 2015).

A future storm surge coupled with higher sea levels could potentially damage, breach, or overtop existing defences, if the rivers were already in flood. During the 1953 storm, for example, the Ouse defences were overtopped by the surge at Wiggenhall, Norfolk as they were near Denver (Steers, 1953). As Steers notes, the situation could also have been much worse: had the surge occurred at the top of the tide, had the storm occurred on a high spring tide, and had the fenland rivers been in flood, the "... whole of the Fens and other similar places..." could have been inundated (ibid: 280). A similar scenario, without the storm surge, had already occurred in the March 1947 floods.

While the 1953 event provides a benchmark for these types of events, a historical review indicates that between 838 and 2020, there were no fewer than 50 storm tides on the North Sea that endangered lives and land around East Anglia (de Kraker, 2002). A similar storm surge event in 1978 was locally more severe to East Anglia than the 1953 storm, and in 1978, as opposed to 1953, Cambridgeshire was directly hit along the River Nene at Wisbech. More than 1000 people were forced to evacuate when the river burst its banks, and damage occurred when the Clarkson Geriatric Day Hospital was inundated. Following the floods, the hospital had to close for weeks for repairs. The 1978 storm surge remains less infamous than the 1953 floods, because damage was much less severe in other parts of the country. Regardless, it shows that the Cambridgeshire \& Peterborough region can be hit by a major storm tide even with the defences that have been improved since 1953 .

Future sea level rise will undoubtedly impact this risk. Yet, because these events represent the confluence of many different factors, they are extremely hard to predict. The UKCP 18 data shows a modest sea level rise by the end of the century, between 0.29 and $1.15 \mathrm{~m}$ in the least extreme and most extreme percentiles within the RCP 2.6 \& 8.5 scenarios respectively. Researchers have shown that while there is a potential for changes in the severity of future storm surge events (Palmer et al., 2018), the UKCP18 model could not accurately predict if storm surges will become more severe (UKCP18 Factsheet: Sea Level Rise and Storm
Surge, 2018). Although difficult to predict, overtopping or breaching of the river and tidal defences, at any point in the region, from either tidal, fluvial, or combinational flooding (as in 1978) could lead to the rapid inundation of a large number of structures, particularly in the north of the region, and could flood good quality farmland with saline water that would be extremely difficult to remove as some areas lie as much as $8 \mathrm{~m}$ below sea level (River Nene Catchment Flood Management Plan: Managing Flood Risk, 2009; Great Ouse Catchment Flood Management Plan: Managing Flood Risk, 2011).

\section{Risk of overheating}

In addition to the risk of greater future flooding events, the region will also certainly face overheating issues, particularly in the summer months. The daily maximum air temperature averaged across the region, would likely be above $36^{\circ} \mathrm{C}$ in one year out of 20 by mid-century within the RCP 2.6 scenario. It would likely be $37.5^{\circ} \mathrm{C}$ in the RCP 8.5 scenario, with projections for other scenarios falling in between (Fig. 1). This is comparable to the high of $38.7^{\circ} \mathrm{C}$ recorded on 25 July, 2019, in Cambridge Botanical Gardens. The ranges of the projections in Fig. 1 show highs could be much hotter than the median projection. By the end of the century, the summer daily maximum air temperature would likely be at least $36^{\circ} \mathrm{C}$ in RCP 2.6 or at least $41^{\circ} \mathrm{C}$ in RCP 8.5 in one year out of 20 .

During the summer of 2019, in which England experienced record-breaking heat, 892 excess deaths were recorded. Yet aside from the obvious risks to the health of the population during these extreme heat events, we could also expect to see a loss in productivity across a range of industries (A Summary of Climate Change Risks for the East of England, 2012; Brimicombe et al., 2021). Furthermore, prolonged extreme heat events can cause impacts on transport, potentially buckling rail tracks and reducing the safe loading of aircraft. It can also impact the demand for water resources, leading to further risks of over-abstraction and drought conditions (UKCP18 Factsheet: Temperature, 2019).

Additionally, hotter summers may be generally better for agricultural productivity in the region given enough water. However, these conditions can increase the risk of agricultural pests and diseases. Well-documented and marked changes in the distributions of several orders of insects indicate the effect of climate change on migrant insects which may damage both crops and native plant species (Sparks et al., 2007). Insects may therefore be able to expand their ranges into areas where vegetation has not coevolved defence mechanisms. In general, climate change and overheating will drive changes in the compositions of communities leading to unpredictable changes in ecosystem function and services (Schweiger et al., 2010). Further, climate-induced stresses like potential drought may render 
plants more vulnerable to new species of opportunistic herbivore (Cannon, 1998). Many types of deciduous trees may also be at increased risk of disease given warmer summer temperatures (Sturrock et al., 2011).

\section{Risk from low river \& aquifer levels}

The effects of heat waves may be most keenly felt when coupled with the effects of drought. As the UKCP 18 climate data show both hotter and drier summers, management of water resources will become more difficult in upcoming years. As the urban footprint grows in Cambridgeshire \& Peterborough, a greater number of people will depend upon water resources. Yet currently, as an example, abstraction in Cambridge reduces water levels in the River Cam by around half its average natural flow (Adams, 2020). The potential for greater future abstraction coupled with lower summer rainfall may negatively impact people, industry, and biodiversity and the quality of the natural environment across the region. This will necessitate mitigation through greater storage of winter rainfall and adaptation through behavioural change.

Biodiversity, particularly in the region's chalk streams, could be impacted by drought combined with warmer conditions. These streams are major centres of biodiversity, home to many nationally rare and threatened species. Fed by chalk aquifers, healthy chalk streams are crystal-clear and maintain water temperatures around $10^{\circ} \mathrm{C}$ year-round. Many species found in them are highly sensitive to fluctuations in temperature, sediment, and pollution (Hawksley \& Mungovan, 2020). Habitat destruction through higher temperatures and lower flows could destroy these populations.

\section{Risk of further depletion of natural carbon storage areas}

The region contains a large proportion of the UK's lowland peat. When drained, peatland is a major emitter of carbon dioxide. $\mathrm{CO} 2$ emission from peatland is dependent upon the water table and the quantity of carbon in the top layer of the soil. The largest abatement of these emissions is achieved by rewetting and restoration to a near-natural state (Evans et al., 2017); however, restoration is not always possible, and drained peatland is often valuable agricultural land. Although drainage systems control the water table, lowland peat may also degrade more quickly with warmer summers (Natural England, 2010). As deep peats shrink, drainage costs rise, which means that in some places continued agricultural use is not sustainable anyway (Natural England, 2010). While one-third of the East Anglian region is currently below sea level, that figure may double by the end of the century due to subsidence from additional peat drying (Adams, 2020).

Baseline national targets by the Committee on Climate Change (CCC) would see $60 \%$ of lowland peat rewetted or sustainably managed by 2050 . The CCC has suggested that lowland peat restoration should receive public funding and would be integrated into carbon markets once emissions reductions can be verified effectively (Committee on Climate Change, 2020). There is some uncertainty in emissions factors, as well as the extent and depth of remaining peatland; however, this should not be allowed to delay the adoption of appropriate sustainable management practices.

\section{Acknowledgements}

This report would not have been possible without the generous advice and feedback of our partners at the Committee on Climate Change, the Environment Agency, and the Cambridgeshire County Council. Kay Johnstone and Jens Evans at the Environment Agency, Kathryn Brown, at the Committee on Climate Change, Adrian Gault, consultant to the Cambridgeshire \& Peterborough Independent Commission on Climate, and Adrian Cannard, Strategic Planner at the Cambridgeshire \& Peterborough Combined Authority, gave us early guidance on the methodology used in this report and supplied feedback on the final draft of the report. Julia Beeden, Flood Risk \& Biodiversity Business Manager at the Cambridgeshire County Council, provided early guidance on existing data sets that would best suit this work and generously arranged a number of meetings with her colleagues at both the Cambridgeshire County Council and the Environment Agency. Hilary Ellis, Principal Sustainable Drainage Officer \& Flood Risk Contract Manager at the County Council, imparted data related to 'wetspots' around the region and helped provide feedback on the report. Jess Prest, SuDS \& Flood Risk Officer at the county council, extended helpful feedback on the final draft of the report. Paul Burrows, Flood \& Coastal Risk Manager for East Anglia at the Environment Agency, and Cameron Adams, Sustainable Places Account Manager at the Environment Agency, gave us a number of sources of evidence related to future impacts on the region due to climate change. Emily Bolton, Climate Change Officer at the Cambridgeshire County Council, provided us with a number of contacts. Quentin Carroll, historic environment team manager at the County Council, Philip Clark, Green Spaces Manager at Cambridgeshire County Council, Chris Bowden, an environmental consultant with the County Council, and John Nash, Rural Estate Manager at Cambridgeshire County Council, pointed us in the direction of important resources regarding peat, land management, and biodiversity across the region. We are additionally grateful to Julia King, Laura Diaz Anadon, Rhiannon Osborne, John Shropshire, Lynne Sullivan, Richard Astle, Russell Picot, Jane Peterson-Todd, and the other members of the Cambridgeshire \& Peterborough Independent Commission on Climate for their helpful comments on our draft report. 


\section{References}

1947 UK River Floods: 60-Year Retrospective. (2007). Risk Management Solutions. https://forms2.rms.com/rs/729-DJX-565/ images/fl_1947_uk_river_floods.pdf

Arnbjerg-Nielsen, K., Willems, P., Olsson, J., Beecham, S., Pathirana, A., Gregersen, I.B., Madsen, H., and Nguyen, V.T.V. (2013). Impacts of climate change on rainfall extremes and urban drainage systems: A review. Water Science and Technology 68(1), 16-28. doi: 10.2166/wst.2013.251

A Summary of Climate Change Risks for the East of England. (2012). Sustainability East. http://www.greensuffolk.org/assets/ Greenest-County/Adaptation/General/Summary-of-climatechange-risks-to-East-of-England.pdf

Adams, C. et al (2020). Defra Group Response to the Independent Climate Change Commission's Call for Evidence.

Baxter, P. J. (2005). The east coast Big Flood, 31 January-1 February 1953: A summary of the human disaster. In Philosophical Transactions of the Royal Society A: Mathematical, Physical and Engineering Sciences (Vol. 363, Issue 1831, pp. 1293-1312). Royal Society. https://doi.org/10.1098/rsta.2005.1569

Brimicombe, C., Porter, J. J., Di Napoli, C., Pappenberger, F., Cornforth, R., Petty, C., \& Cloke, H. L. (2021). Heatwaves: An invisible risk in UK policy and research. In Environmental Science and Policy (Vol. 116, pp. 1-7). Elsevier Ltd. https:// doi.org/10.1016/j.envsci.2020.10.021

Cannon, R.J. (1998). "The implications of predicted climate change for insect pests in the UK, with emphasis on non-indigenous species". Global Change Biology 4(7): 785 - 796. https://doi. org/10.1046/j.1365-2486.1998.00190.x

Committee on Climate Change, (2020) Sixth Carbon Budget.

Dale, B., \& Stylianou, N. (2020). What will climate change look like in your area? - BBC News. BBC News \& the Met Office. https://www.bbc.co.uk/news/resources/ idt-d6338d9f-8789-4bc2-b6d7-3691c0e7d138

Environment Agency. (n.d.). The Ouse Washes Flood Storage Reservoir. http://ousewashes.org.uk/wp-content/uploads/2016/05/ Ouse-Washes_updated.pdf

Evans, Chris, et al (2017). Implementation of an Emissions Inventory for UK Peatlands. Centre for Ecology and Hydrology. https:// www.fensforthefuture.org.uk/admin/resources/downloads/ beisukpeatlandghgemissions-2019.pdf

de Kraker, A. M. J. (2002). Historic Storms in the North Sea Area, an Assessment of the Storm Data, the Present Position of Research and the Prospects for Future Research. In Climate Development and History of the North Atlantic Realm (pp. 415-434). Springer Berlin Heidelberg. https://doi. org/10.1007/978-3-662-04965-5_27

Great Ouse Catchment Flood Management Plan: Managing flood risk. (2011). Environment Agency. https://www.gov.uk/government/ publications/great-ouse-catchment-flood-management-plan

Hawksley, R. \& Mungovan, R. (2020). Greater Cambridge chalk streams project report. Cambridge City Council \& Cambridge Water.

Hersbach, H, Bell, B, Berrisford, P, et al. (2020). The ERA5 global reanalysis. Q J R Meteorol Soc. 146: 1999- 2049. https://doi. org/10.1002/qj.3803

Kendon, M., McCarthy, M., Jevrejeva, S., Matthews, A., \& Legg, T. (2019). State of the UK climate 2018. International Journal of Climatology, 39(S1), 1-55. https://doi.org/10.1002/joc.6213
Lowe, J. A., Bernie, D., Bett, P., Bricheno, L., Brown, S., Calvert, D., ... \& Belcher, S. (2018). UKCP18 science overview report. Exeter, UK: Met Office Hadley Centre.

Natural England. (2010). England's peatlands: carbon storage and greenhouse gases, Report NE257. http://publications.naturalengland.org.uk/publication/30021

Palmer, M., Howard, T., Tinker, J., Lowe, J., Bricheno, L., Calvert, D., Edwards, T., Gregory, J., Harris, G., Krijnen, J., Pickering, M., Roberts, C., \& Wolf, J. (2018). UKCP18 marine report.

Prichard, B. (2013). The North Sea surge and east coast floods of 1953. Weather, 68(2), 31-36. https://doi.org/10.1002/ wea. 2044

Ritchie, J., \& Dowlatabadi, H. (2017). Why do climate change scenarios return to coal? Energy, 140, 1276-1291. https:// doi.org/10.1016/j.energy.2017.08.083

River Nene Catchment Flood Management Plan: managing flood risk. (2009). Environment Agency. https://www. gov.uk/government/publications/river-nene-catchment -flood-management-plan

Schweiger, O., Biesmeijer, J.C., Bommarco, R., Hickler, T., Hulme, P.E., Klotz, S., Kühn, I., Moora, M., Nielsen, A., Ohlemüller, R., Petanidou, T., Potts, S.G., Pyšek, P., Stout, J.C., Sykes, M.T., Tscheulin, T., Vilà, M., Walther, G.-R., Westphal, C., Winter, M., Zobel, M. and Settele, J. (2010). "Multiple stressors on biotic interactions: how climate change and alien species interact to affect pollination." Biological Reviews, 85: 777-795. https://doi.org/10.1111/j.1469-185X.2010.00125.x

Smith, M. J., \& Phillips, I. D. (2013). Winter daily precipitation variability over the East Anglian region of Great Britain and its relationship with river flow. International Journal of Climatology, 33(9), 2215-2231. https://doi.org/10.1002/joc.3594

Sparks, T.H., Dennis, R.L., Croxton, P.J. \& Cade, M. (2007). Increased migration of Lepidoptera linked to climate change. European Journal of Entomology, 104(1), p.139.

Steers, J. A. (1953). The East Coast Floods. The Geographical Journal, 119(3), 280. https://doi.org/10.2307/1790640

Sturrock, R.N., Frankel, S.J., Brown, A.V., Hennon, P.E., Kliejunas, J.T., Lewis, K.J., Worrall, J.J. and Woods, A.J. (2011). "Climate change and forest diseases." Plant Pathology, 60: 133-149. https://doi.org/10.1111/j.1365-3059.2010.02406.x

Surface Water Management Plans. (2011). Cambridgeshire County Council. https://www.cambridgeshire.gov.uk/ business/planning-and-development/flood-and-water/ surface-water-management-plans

Troshka, L., Power, K., Green, R., David, A., Mansell, P., Jones, A., \& Crompton, A. (2018). Climate Change Risk and Resilience Scoping Study.

UK Climate Change Risk Assessment 2017. (2017).

UKCP18 Factsheet: Sea level rise and storm surge. (2018). www.gov.uk/ guidance/flood-risk-assessments-climate-change-allowances

UKCP18 Factsheet: Temperature. (2019). https://www.metoffice. gov.uk/binaries/content/assets/metofficegovuk/pdf/research/ ukcp/ukcp18-fact-sheet-temperature.pdf

Wadey, M. P., Haigh, I. D., Nicholls, R. J., Brown, J. M., Horsburgh, K., Carroll, B., Gallop, S. L., Mason, T., \& Bradshaw, E. (2015). A comparison of the 31 January-1 February 1953 and 5-6 December 2013 coastal flood events around the UK. Frontiers in Marine Science, 2(NOV), 84. https://doi. org/10.3389/fmars.2015.00084 